\title{
O USO DA TERRA E DOS RECURSOS HÍDRICOS DA BACIA DO CÓRREGO FACÃO, PANTANAL DE CÁCERES, MATO GROSSO
}

\author{
Josiane São Bernardo Cruz ${ }^{(a)}$; Celia Alves de Souza ${ }^{(b) ;}$ William Cosme da Silveira de \\ Paula $^{(\mathrm{c})}$;Vinicius Neves da Silva ${ }^{(\mathrm{d})}$ \\ (a) Mestrando em Ciências Ambientais Universidade do Estado de Mato Grosso (UNEMAT) - e-mail: \\ <josiane_bernardo05@hotmail.com> \\ (b) Professora Departamento de Geografia (UNEMAT) - e-mail: celiaalvesgeo@globo.com \\ (c) Departamento de Geografia (UNEMAT) - e-mail: willtmt15@gmail.com \\ (d) Departamento de Geografia (UNEMAT) - e-mail: vinicius.k99@gmail.com
}

\section{EIXO: BACIAS HIDROGRÁFICAS E RECURSOS HÍDRICOS: ANÁLISE, PLANEJAMENTO E GESTÃO}

\begin{abstract}
Resumo
Este estudo tem como objetivo identificar o uso da terra e dos recursos hídricos da bacia do córrego Facão, no município de Cáceres, MT. À metodologia utilizada para o levantamento do uso da terra, consistiu no levantamento de informações em arquivos e repartição publica e visitas in loco com aplicação de questionários e anotados pequenos relatos de alguns moradores. A bacia hidrográfica do córrego Facão perpassa os assentamentos Facão e Facão Bom Jardim e as fazendas Rancho Verde e Ressaca. Os proprietários que residem no alto e médio curso da bacia são agricultores que usam a terra para o desenvolvimento da agricultura de subsistência e criação de animais. E os recursos hídricos são utilizados para abastecimento doméstico, dessedentação dos animais, piscicultura e irrigação. No baixo curso a terra é utilizada para pecuária extensiva e intensiva e agricultura extensiva. E a água dos córregos é utilizada para dessedentação dos animais.
\end{abstract}

Palavras chaves: Gestão; Uso; Recursos hídricos.

\section{INTRODUÇÃO}

A bacia hidrográfica é uma unidade territorial drenada pelo rio/córrego e seus afluentes, podendo ser compreendida como um conjunto de elementos físicos, bióticos e socioeconômico inter-relacionados de onde o homem utiliza o solo, a água, a vegetação no desenvolvimento das suas atividades para sobreviver, e é vista como uma unidade de planejamento e gestão (MAGALHÃES JÚNIOR, 2007; CUNHA; GUERRA, 2009).

E de acordo com a Lei n 9433/1997 essa é a unidade territorial para implementação da Política Nacional e atuação do Sistema Nacional de Gerenciamento de Recursos Hídricos. A gestão deve ser descentralizada e solicita a participação do Poder Público, dos usuários e das comunidades em geral. E que a água é considerada como recurso hídrico de uso múltiplo, sendo prioritário para o consumo humano e a dessedentação de animais. 
XVII Simpósio Brasileiro

de Geografia Física Aplicada

I Congresso Nacional

de Geografia Física
OS DESAFIOS DA GEOGRAFIA FÍSICA NA FRONTEIRA DO CONHECIMENTO

Instituto de Geociências - Unicamp

Campinas - SP

28 de Junho à 02 de Julho de 2017

Sobre o uso da terra da bacia o Código Florestal Brasileiro sanciona que as áreas marginais dos cursos d'água são áreas de Preservação Permanente (APPs) não podem ser ocupadas. Observa em muitos estudos, no entanto, o não cumprimento da legislação, como os apresentados por Silva e Souza (2012), feito no rio Paraguai. Essas pesquisadoras observaram que quase toda cobertura vegetal foi retirada das margens, dando lugar a residências, sítios e comércios.

A bacia hidrográfica do córrego Facão está localizada no município de Cáceres e compreende áreas dos assentamentos Facão e Facão Bom Jardim e das fazendas Rancho Verde e Ressaca/Grendene. Essa bacia atualmente está ocupada, no seu alto e médio curso, por pequenos proprietários que usam a terra para agricultura, criação de gado, piscicultura, áreas de lazer. No baixo curso, há duas fazendas que são voltadas para a criação de bovinos de forma intensiva e extensiva, plantio de soja e milho em larga escala.

Alguns estudos destacam-se sobre uso e ocupação de bacias hidrográficas. No contexto regional, destacam os trabalhos de Andrade et al. (2012) analisaram a bacia hidrográfica do rio Jauru no município de Cáceres; Silva e Souza (2012) avaliaram a ocupação e a degradação das margens do rio Paraguai; Santos (2013) pesquisaram a bacia hidrografia do córrego Cachoeirinha no município de Cáceres.

Diante do exposto, a pesquisa objetiva fazer um levantamento sobre o uso da terra e dos recursos hídricos da bacia hidrográfica do córrego Facão.

\section{MATERIAL E MÉTODO}

\section{1 Área de Estudo}

A bacia hidrográfica do córrego Facão, afluente do rio Paraguai, localiza a sudeste da cidade de Cáceres, possui uma área de $149,81 \mathrm{~km}^{2}$, está localizada entre as coordenadas $16^{\circ} 08^{\prime} 48,09^{\prime \prime} \mathrm{S}$ a $16^{\circ} 10^{\prime}$

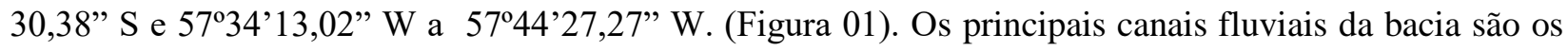
córregos Facão e Sapezal, muito importantes para o abastecimento da população local. 


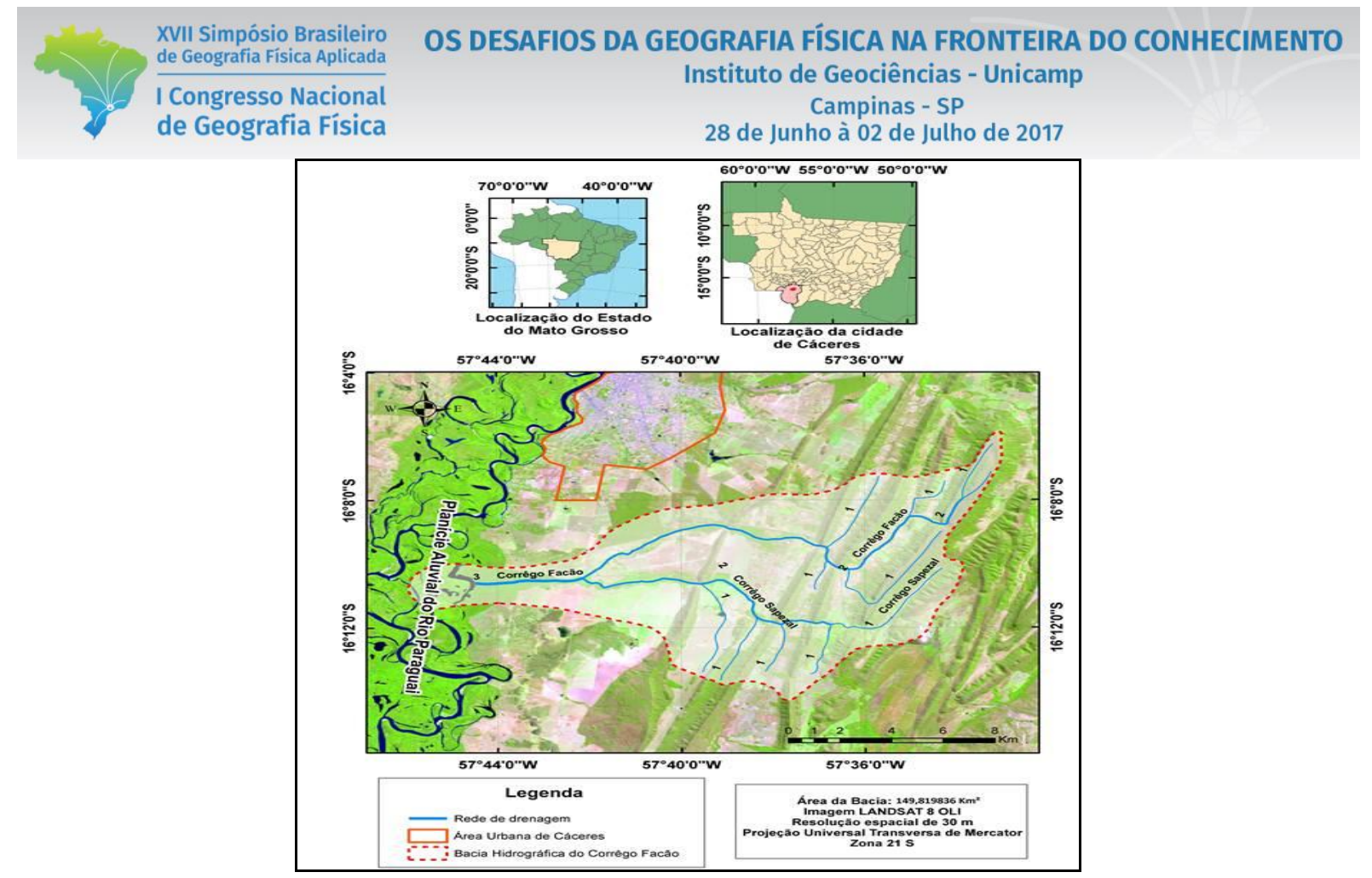

Figura 1: Mapa de localização da bacia do córrego Facão

\subsection{Procedimentos metodológicos}

\subsubsection{Levantamento da ocupação e uso da bacia do córrego Facão}

O levantamento do uso da terra e dos recursos hídricos da bacia hidrográfica do córrego Facão foi realizado através de analise bibliográfico e visitas in loco com aplicação de questionário semiestruturado aos moradores, conforme Boni e Quaresma (2005) e anotados pequenos relatos de alguns moradores.

O mapeamento foi realizado a partir de base cartográfica obtida no catálogo de imagens disponíveis no site do Ministério do Meio Ambiente (MMA), CPRM. Foram vetorizadas classes e atributos pelo software ArcGis 10.2.2, usando como base dados secundários (MMA, CPRM).

A visita nas propriedades para observação da ocupação e uso da terra e aplicação dos questionários semiestruturado. Foram entrevistados 23 proprietários, sendo 11 no alto, 11 no médio e somente um no baixo curso da bacia hidrográfica do córrego Facão porque existem apenas duas fazendas e somente um morador concordou em conceder a entrevista. Dentre os entrevistados, alguns não são proprietários dos sítios ou fazendas, são pessoas pagas para cuidarem dos locais porque o proprietário mora na cidade. 


\section{RESULTADOS E DISCUSSÕES}

\subsection{Analise dos dados da entrevista aplicado aos moradores da bacia hidrográfica do córrego Facão}

A área da bacia hidrográfica do córrego Facão abrange o assentamento Facão e Facão Bom Jardim (Comunidade Boa Esperança, São José e Bom Jardim) que é distribuído a 253 famílias por intermédio do financiamento rural. Essas famílias desenvolvem a agricultura familiar e pecuária extensiva e as fazendas Rancho Verde e Ressaca onde desenvolvem a pecuária extensiva e intensiva e agricultura (Figura 02).

Sendo o córrego Facão de extrema importância para a população que vive em seu entorno, principalmente no alto curso da bacia, local de onde a população usa água - proveniente do córrego e das minas - para uso doméstico, dessedentação dos animais, recreação e irrigação.

Figura 02: Mapa de localização dos assentamentos Facão e Facão Bom Jardim, das fazendas Racho Verde e Ressaca.

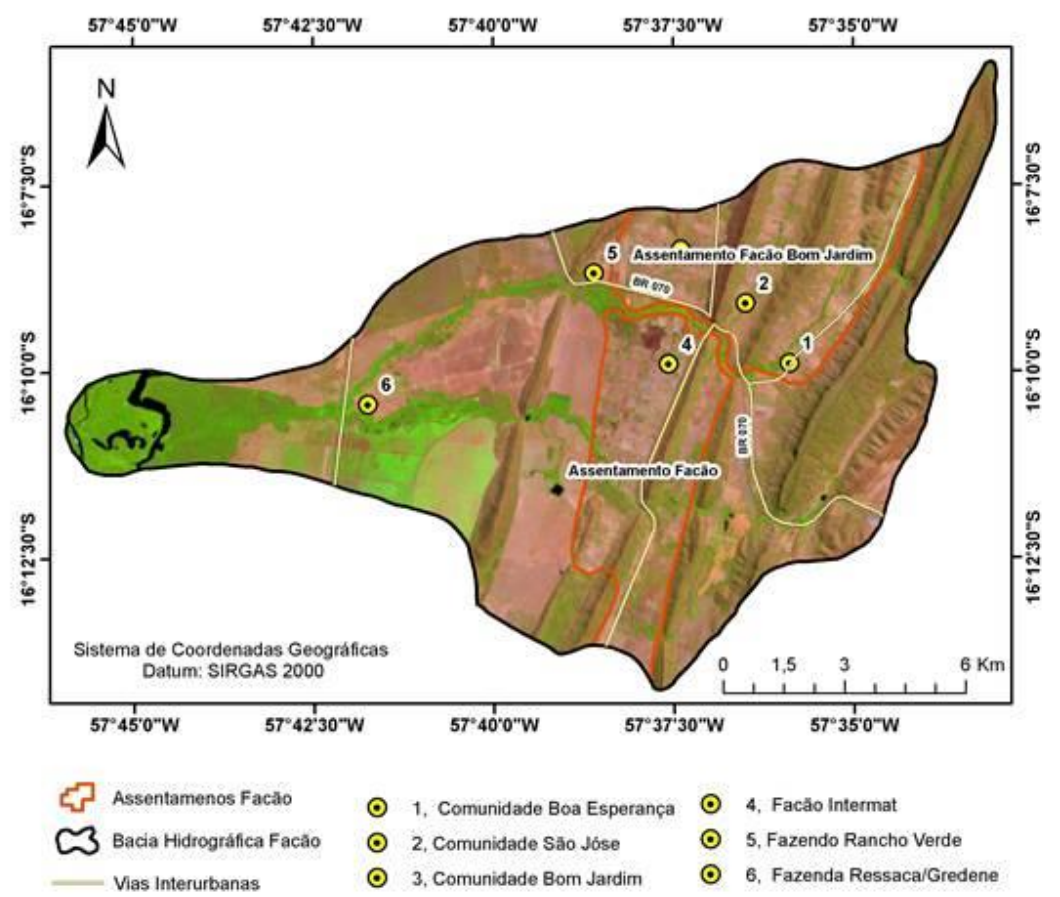

No alto curso da bacia hidrográfica, encontra-se o assentamento Facão, as comunidades Boa Esperança e São José. No médio curso, o assentamento Facão e a comunidade Bom Jardim. No baixo curso, a fazenda Rancho Verde e Ressaca/Grendene. 


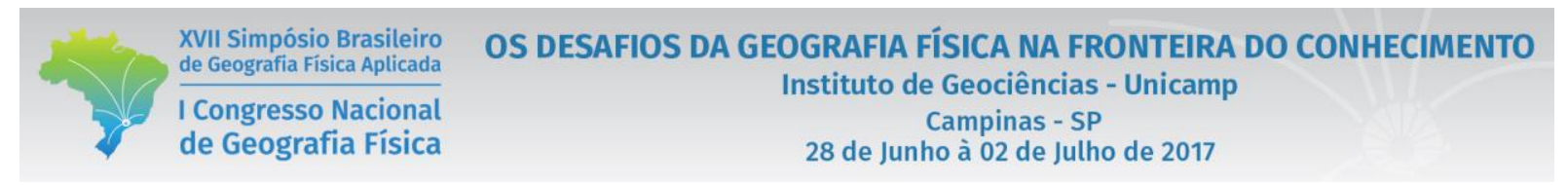

$\mathrm{O}$ alto curso da bacia hidrográfica abrange os vales e as serras da Província Serrana, encontra as principais nascentes do córrego Facão e também se encontram duas cachoeiras, a Cachoeirinha e Facão locais que a população utiliza para lazer e coleta de água.

O uso da terra nesse compartimento é realizado nos vales entre as serras da Província Serrana. Nessa seção foram entrevistados 11 proprietários do assentamento Facão e Facão Bom Jardim, nas comunidades Boa Esperança e São José. Os pequenos agricultores residem e trabalham nas propriedades entre o período de um a dez anos. Esses agricultores realizam atividades de subsistência, cultivando a mandioca, milho, feijão, melancia, banana entre outras culturas. Algumas propriedades possuem próximo à residência, pomar e plantas medicinais e ornamentais.

A atividade predominante no alto curso da bacia hidrográfica é o cultivo de pastagem, destinada à criação de gado. A agricultura desenvolvida é basicamente de subsistência (cana, milho, mandioca) com manejo de solo de baixo nível tecnológico, e no entorno das casas desenvolve a horta, o pomar e plantas ornamentais (Figura 3).

Figura 3: Frequência absoluta das respostas sobre o uso da terra da bacia hidrográfica do córrego Facão município de Cáceres, MT

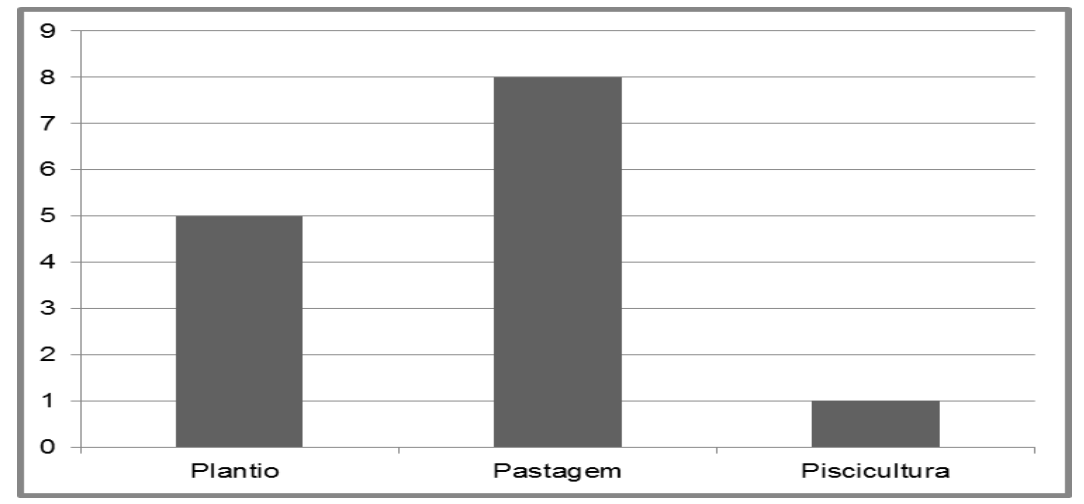

Nesse compartimento da bacia hidrográfica, a maioria das propriedades possui cursos fluviais em sua propriedade. Dos 11 entrevistados, somente uma propriedade não possui curso de água, porém utiliza a água encanada das nascentes do córrego Facão.

Dentre as propriedades com cursos d'agua, somente quatro alegam usar a água do córrego para usos diversos (uso doméstico, dessedentação dos animais, piscicultura e recreação) (Figura 4). Os que não usam o córrego possuem poços artesianos e comuns ou água encanada da mina. Quando questionados pelo não uso da água do córrego, alegaram a falta da água no período de estiagem. Na propriedade que desenvolve a piscicultura o proprietário alegou que o tanque é abastecido com a água do córrego, havendo 
XVII Simpósio Brasileiro

de Geografia Fisica Aplicada

I Congresso Nacional

de Geografia Física

\section{OS DESAFIOS DA GEOGRAFIA FÍSICA NA FRONTEIRA DO CONHECIMENTO \\ Instituto de Geociências - Unicamp \\ Campinas - SP \\ 28 de Junho à 02 de Julho de 2017}

manejo de entrada e saída da água do tanque para que retorne novamente para dentro do córrego (Figura $5)$.

Embora os demais entrevistados alegaram o não uso da água do córrego, em algumas propriedades pôde-se perceber que o córrego é utilizado para bebedouro de gado.

Figura 4: Frequência absoluta das respostas sobre o uso da água dos córregos da bacia hidrográfica do córrego Facão, município de Cáceres, MT.

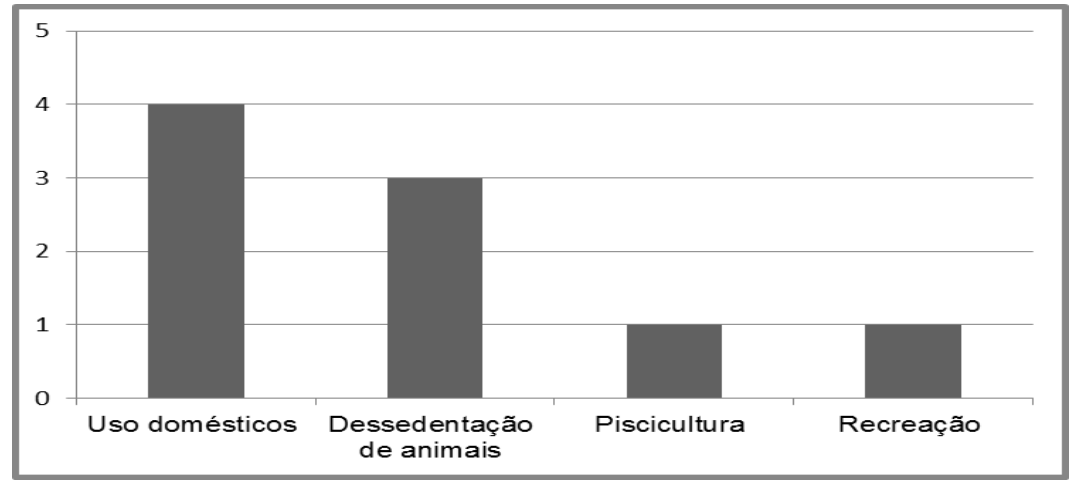

Figura 5: Represa de um dos sitios da bacia hidrgrafica do córrego Facão

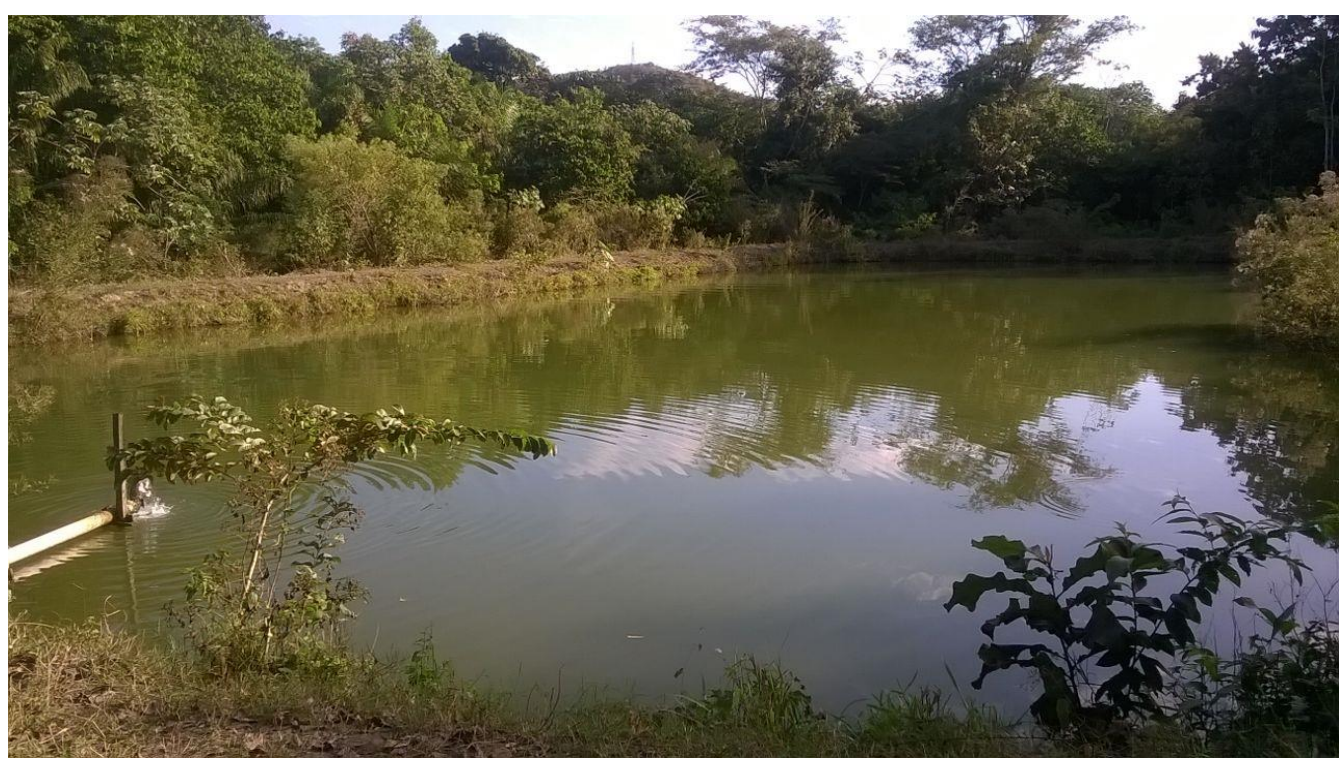

Fonte: Josiane São Bernardo da Cruz

Data: setembro/2016

Embora a área do entorno dos córregos esteja sendo ocupada, com bastante frequência, todos os entrevistados alegaram que as atividades desenvolvidas não prejudicam as pessoas que usam a jusante, 


\section{OS DESAFIOS DA GEOGRAFIA FÍSICA NA FRONTEIRA DO CONHECIMENTO \\ Instituto de Geociências - Unicamp \\ Campinas - SP \\ 28 de Junho à 02 de Julho de 2017}

pois preservam-na. Ressalta-se que, na bacia hidrográfica do córrego Facão, algumas propriedades utilizam o córrego para recreação, portanto não foi possível entrevistá-los.

De acordo com o que demonstra a com as informações, a água mais utilizada é encanada das minas, mesmo que somente duas pessoas concedeu a entrevista é bem visível na comunidade Boa Esperança as encanações vinda das minas na serra, e também do próprio córrego Facão para o abastecimento das residências dos moradores. O uso de poço artesiano e comum e bem praticado na comunidade São José, pois o córrego encontrado nessa comunidade é um dos afluentes do córrego Facão, que passa em alguns sítios e possui pouca água (figura 6).

Figura 6: Frequência absoluta sobre a origem da água para o consumo humano da população da bacia hidrográfica do córrego Facão, município de Cáceres, MT

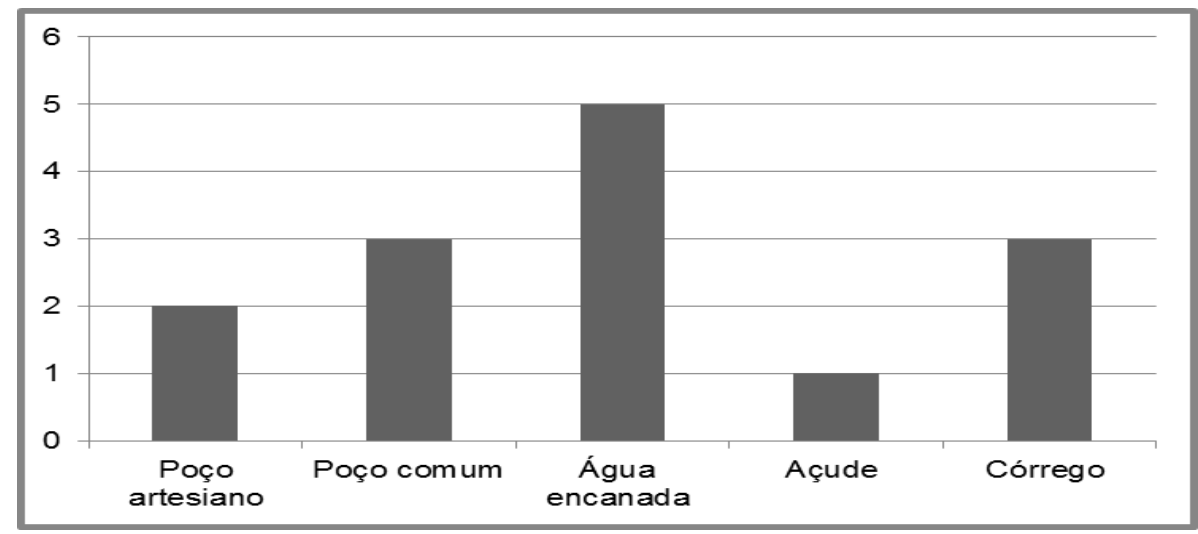

Dentre as pessoas entrevistadas, 72,72\% delas disseram que houve mudanças no córrego Facão e em seus afluentes durante o tempo que conhecem esse local. A alteração percebida foi a diminuição da água do córrego e, até mesmo, o desaparecimento de algum afluente desse curso d'água.

Quanto à preservação dos cursos de água, 36,36\% dos entrevistados alegaram estarem parcialmente preservados e 45,45\% declararam que está preservado; porém, em algumas propriedades são bem visíveis as degradação do curso d'água. Em um afluente do córrego Facão, na comunidade São José, o assoreamento é intenso, a calha não está mais definida. O pisoteio do gado no entorno compacta o solo, iniciando os processos erosivos de ravinamento (Figura 7).

Figura 7: Local onde o córrego afluente do córrego Facão não possui calha definida devido ao assoreamento 


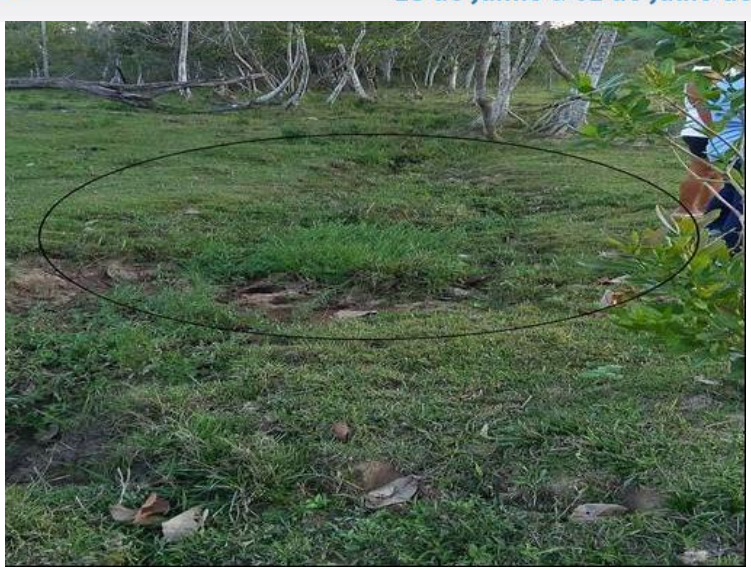

Fonte: Josiane São Bernardo da Cruz

Data: setembro/2016

Estudos realizados por Andrade et al. (2012), efetuados na bacia hidrográfica do rio Jauru, consideraram que a retirada da mata ciliar para a ocupação e usos diversos, comprometeram a quantidade e a qualidade dos cursos d'água, alterando todo processo natural.

Algumas pessoas frisaram a importância da preservação da bacia hidrográfica, pelo fato do córrego ser muito útil para a população local por disponibiliza água para essa população.

No médio curso da bacia hidrográfica, está a comunidade Bom Jardim e uma parte do assentamento Facão. Dentre os moradores desses locais, foram entrevistados 11 proprietários de diferentes faixas etárias. Os sitiantes que lá residem há mais de um ano, são pequenos agricultores que cultivam mandioca, milho, abobora, maracujá, quiabo, pimenta, jiló, banana e também criam suínos, bovinos e galinhas.

De acordo as informações disponibilizadas na figura 8, sobre o tipo de uso da terra, é igualmente usada para pastagem, criação de animais e plantio.

Figura 8: Frequência absoluta das respostas sobre o uso da terra da bacia hidrográfica do córrego Facão, Cáceres, MT

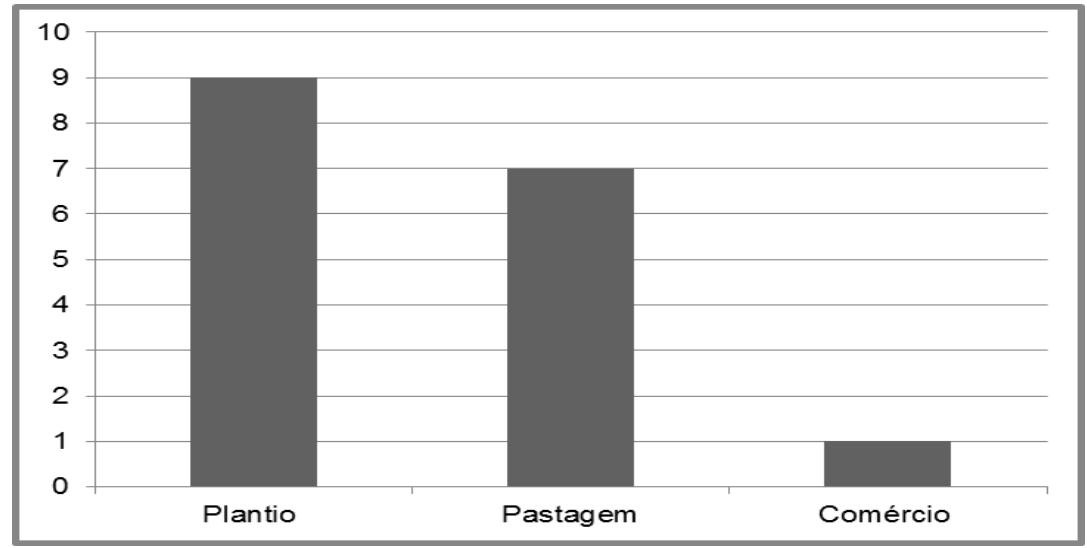




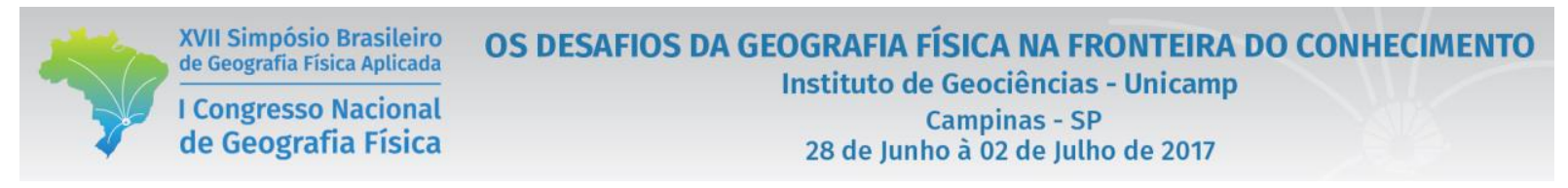

Nesse compartimento da bacia hidrográfica possui dois canais fluviais, o córrego Facão e o Sapezal, embora os entrevistados terem afirmado não possuir cursos d'água e nem olhos d'agua, minas ou nascentes em suas propriedades. Em relação a mudanças no córrego, sete entrevistados disseram que, durante o período de tempo que moram na bacia, não perceberam mudança alguma no córrego. Outros entrevistados, porém, perceberam alterações no córrego, como a diminuição da água e assoreamento do córrego. De acordo com um dos entrevistados, o principal fator que influenciou essas modificações é o desmatamento e o uso da água para irrigação.

A origem da água para o consumo é diverso sendo utilizados poços artesiano e comum, a água encanada e o córrego (Figura 9). Todos utilizam a água da mina para beber e, dos entrevistados que possuem poço artesiano em suas propriedades, quatro alegaram uso da água encanada do córrego para criação de animais, uso doméstico e irrigação.

Figura 9: Frequência absoluta da origem da água para consumo humano da população da bacia hidrográfica do córrego Facão, Cáceres, MT

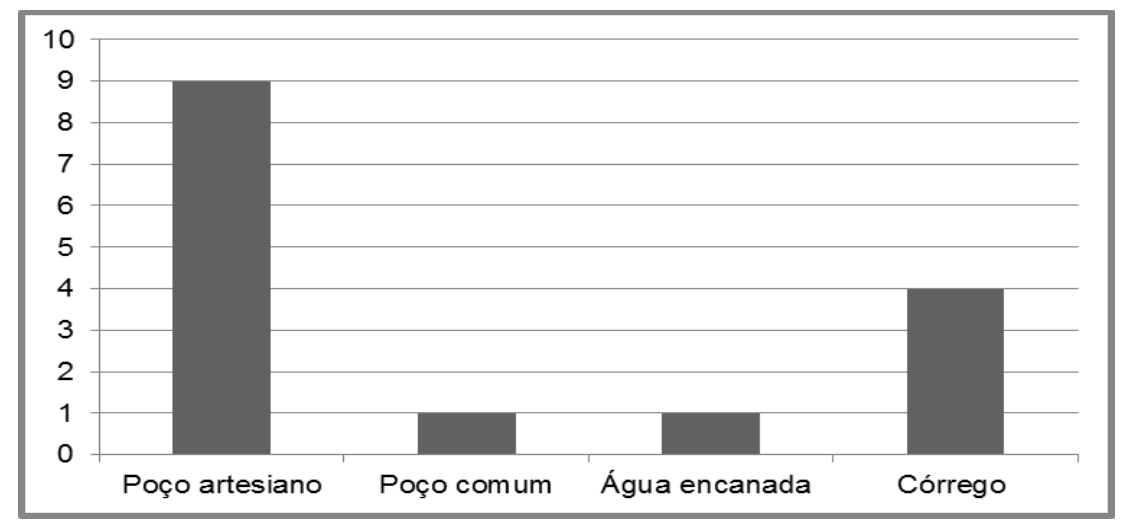

A disponibilidade hídrica subterrânea e a produtividade de poços são os principais fatores de exploração dos aquíferos; mas são necessários alguns cuidados porque o crescimento descontrolado da perfuração de poços tubulares e das atividades antrópicas podem contaminar os aquíferos. Os projetos de proteção de poços são essenciais para o melhoramento dos sistemas de abastecimento d'água urbanos e também para programas de prevenção de contaminação de mananciais de subsuperfícies (BARBOSA, 2007).

Ressalta-se que, no alto e médio curso da bacia hidrográfica, as porções destinadas às Áreas de Preservação Permanente (APPs) nas serras (Província Serrana) estão em bom estado de conservação, pois são impróprias para cultivos e criação de gado. 


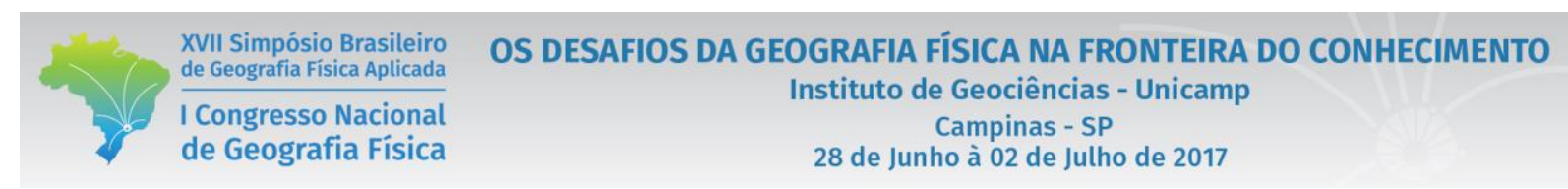

No baixo curso da bacia hidrográfica do córrego Facão, situam-se a Fazenda Rancho Verde e a Fazenda Ressaca, que ocupa a maior área. Uma parte da Fazenda Rancho Verde encontra-se arrendada para a criação de gado de forma extensiva.

Na fazenda Rancho Verde, um entrevistado alegou que, durante o tempo que conhece o córrego, houve diminuição do volume de água. Quando questionado sobre as atividades desenvolvidas, alegou que não causam benefícios e nem prejuízos aos que utilizam a jusante da propriedade. Em sua propriedade, a água para consumo humano é de poço; porém, utiliza a água do córrego para a dessedentação dos animais. A área da fazenda é ocupada com pastagem, e, no entorno do canal fluvial, a mata ciliar encontra-se parcialmente preservada, portanto há trechos em que o canal encontra-se assoreando em virtude do pisoteio do gado nas margens.

A derrubada da vegetação nativa nas margens do rio/córrego e a prática da pecuária, em grande parte extensiva, agravam as condições de erosão em função da compactação do solo, pois o pisoteio do gado dificulta a percolação da água e favorece o escoamento superficial (LEITE; SILVA; HENRIQUE, 2011).

A fazenda Ressaca é uma propriedade de engenho antiga da região e, atualmente, pertence ao grupo Grendene e não está aberta ao público em geral. A esse local não foi permitida a entrada, com a alegação de que, naquele momento não havia autorização ao ingresso de pesquisadores.

Em estudo realizado, Büller (2016) diz que, na entrevista com um funcionário da fazenda Ressaca, esse servidor alegou que não era utilizada a área do entorno do córrego, mas podem ser observados, campos de pastagens para a criação de gado e também áreas de plantio de soja e milho.

O uso inadequado da terra vem gerando, ao longo do tempo, a insustentabilidade dos recursos naturais. O manejo irracional dos solos, muitas vezes, dificulta a produção e compromete o equilíbrio dos ecossistemas (clima, vegetação, geomorfologia, geologia, deflúvio e evapotranspiração) (SANTOS, 2007).

A atividade agropecuária ocasiona eutrofização dos rios ou córregos, devido à grande quantidade de matéria orgânica depositada pelos animais do pasto, como também os fertilizantes da agricultura, os quais chegam ao leito do rio por escoamento superficial ou água subterrânea (CARVALHO; SANTOS; PEIXOTO, 2015).

\subsection{A importância da Gestão dos recursos hídricos da bacia hidrográfica do córrego Facão}

A Lei $n^{\circ} 9.433$ de 8 janeiro de 1997, institui sobre a Politica Nacional de Recursos Hídricos fundamenta que a água e um bem de domínio publico, sendo limitado e dotado de valor econômica, quando escasso o uso prioritário e o consumo humano e a dessedentacao de animais. 


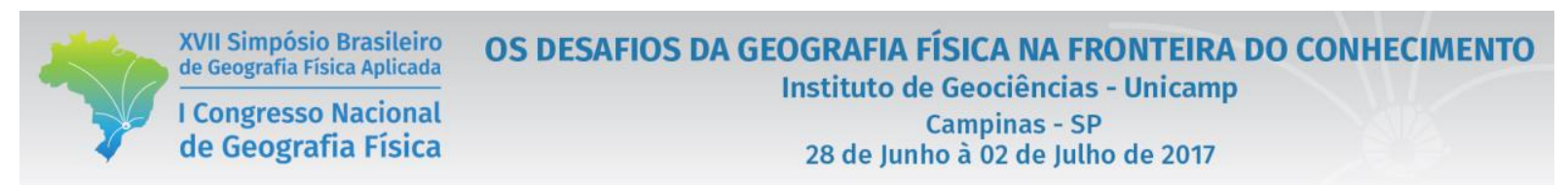

A gestão dos recursos hídricos deve: proporcionar o uso múltiplo da água; e deve ser descentralizada contando com a participação do Poder Publico, dos usuários e das comunidades. Os recursos hídricos da bacia hidrografia do córrego Facão são utilizados pela a população para usos diversos: abastecimentos domésticos, irrigação das culturas agrícolas, recreação, piscicultura e dessedentação dos animais. Portanto para a conservação desses recursos os usuários devem estar atentos aos impactos causados decorrentes ao uso.

Alguns usuários dos recursos hídricos na bacia relataram sobre os conflitos decorrentes ao uso direto do córrego pelos usuários a montante de suas propriedades, pois represaram a água fazendo com que os demais sítios que o córrego perpassa fiquem sem água. Os mesmos procuraram o poder público para resolver a questão em sim, porem não houve retorno. Devido a esse problema grande parte da população, mesmo possuindo canal fluvial na propriedade, optou para o uso das águas subterrâneas através de poço comum e/ou artesiano.

O aumento da demanda da água acarreta os conflitos entre os usuários dos recursos hídricos. Então é necessário uma boa gestão com normas que regulamentam as inter-relações (usuários e recursos hídricos, usuários e usuários) que possa propor a população o uso adequado para a conservação dos recursos hídricos, e que estabeleçam prioridades e regras para a solução dos conflitos (SETTI et al.,2000).

\section{CONSIDERAÇÕES FINAIS}

A aplicação da entrevista foi útil para a obtenção de dados sobre o uso da terra, a utilização dos córregos que compõem a bacia hidrográfica e a percepção dos moradores quanto à mudança ocorrida nos cursos d'água. Houve algumas dificuldades à aplicação do questionário, pois muitas propriedades não foram encontrados os responsáveis, e alguns proprietários não autorizaram a entrada e também recusaramse a fornecer as informações.

Os córregos que compõem a bacia sofreram algumas alterações, podendo ser resultado do uso da terra. As Áreas de Preservação Permanente (APPs) são respeitadas em alguns trechos da bacia hidrográfica; porém alguns afluentes do córrego Facão necessitam de restituição da mata ciliar para evitar o assoreamento, que está em processo acelerado.

Em relação a gestão dos recursos hídricos superficial e subterrâneo, é necessário que o poder público e a população local tenha conhecimento sobre a quantidade e qualidade dos mesmos e os processos necessários para o desenvolvimento dessa gestão. Uma vez que, com a escassez dos recursos 
hídricos superficial, grande parte dos proprietários utilizam os recursos hídricos subterrâneos por intermédio dos poços comuns e artesianos.

\section{REFERÊNCIAS}

ANDRADE, L. N. P.; RITELA, A.; PERETTO, A.; SOUZA, C. A.; MATOS, E. H.; SOUSA, J. B.; ARAÚJO, R. M.; SANTOS, Z, G.; SOUZA, M. A.; MEIRELES, Z. G. Uso e ocupação da bacia hidrográfica do rio Jauru. Org.: SOUZA, A.S.; SOUZA, B. S.; ANDRADE, L. N. P.S. Bacia hidrográfica do rio Jauru Mato Grosso - dinâmica espacial e impactos associados, São Carlo: Editora RiMa, 2012.

BARBOSA, L. K. L. Zoneamento de aquíferos através da delimitação de perímetros de proteção de poços de abastecimento público de água: o caso da cidade de João Pessoa - PB. 2007. 87p. Dissertação (Mestrado em Engenharia Urbana), Universidade Federal da Paraíba, João Pessoa.

BONI, V.; QUARESMA, S. J. Aprendendo a entrevistar: como fazer entrevistas em Ciências Sociais. Revista Eletrônica dos Pós-Graduandos em Sociologia Política da UFSC, v. 2, n. 1 (3), 2005, p. 68-80.

BÜLLER, B. F. A influencia da geologia e do uso e ocupação da terra na qualidade da água e composição sedimentar do córrego Jacobina, município de Cáceres-MT. 2016. 158 p. Dissertação (Mestrado em Ciências Ambientais), Universidade do Estado de Mato Grosso.

CARVALHO, T.B; SANTOS, R. B.; PEIXOTO, J. S. Uso e ocupação do solo na bacia hidrográfica do rio Jacaré, Sergipe. Anais, $2^{\circ}$ Congresso Internacional-RESAG, Gestão da água e monitoramento ambiental- 9 a 11 de dezembro 2015. Aracaju- SE.

GIL, A. C. Métodos e técnicas de pesquisa social. Ed. 2, São Paulo: Editora Edgar Blucher Ltda., 2002.

INCRA - Instituto Brasileiro de Geografia e Estatística. Relatório de Atividades: INCRA 30 anos. Brasília, 2015. Disponível em: <www.incra.gov.br/arquivos/0172500473.pdf>. Acesso: maio/ 2016.

MAGALHÃES JÚNIOR, A. P. Indicadores Ambientais e Recursos Hídricos: realidade e perspectivas para o Brasil a partir da experiência francesa. Rio de Janeiro: Bertrand Brasil, 2007.

SILVA, R. V., SOUZA, C. A. Rio Paraguai: ocupação e degradação no perímetro urbanos de Cáceres - MT. In: SOUZA, C. A. (Org.) Bacias Hidrográficas do rio Paraguai-MT: Dinâmica das águas, uso e ocupação e degradação ambiental. São Carlos: Editora Cubo, 2012.

SANTOS, M. A Dinâmica Fluvial Da Bacia Hidrográfica Do Córrego Cachoeirinha No Município De Cáceres MTBrasil. Revista Enciclopédia Biosfera, Goiânia, v. 9, n. 17, p.3160,2013.

SETTI, A. A.; LIMA, J. E. F. W.; CHAVES A. G. M. PEREIRA, I. C. Introdução ao gerenciamento de recursos hídricos. $2^{a}$ ed. Brasília: Agência Nacional de Energia Elétrica, Superintendência de Estudos e Informações Hidrológicas, 2000.

SILVA, R. V., SOUZA, C. A. Rio Paraguai: ocupação e degradação no perímetro urbano de Cáceres-MT. In: SOUZA, C. A.(Org.) Bacias hidrográficas do rio Paraguai-MT: Dinâmicas das águas, uso e ocupação e degradação ambiental. São Carlos: Editora Cubo, 2012.

SOUZA, C. A.; SOUSA, J. B. Bacia hidrográfica do córrego Piraputanga, Cáceres, Mato Grosso-Brasil: Caracterização ambiental e dinâmica fluvial. Geoaraguaia, Barra do Garças-MT, v. 4, n. 1, p.83-103, 2014. 